is to gain a better understanding of the concerns and career paths of women in psychiatry in different regions and countries. This is vital for those responsible for training and for structuring academic and healthcare systems (Borus, 2004), and will allow the design and testing of interventions at various levels. Women often need support systems at home and at work to allow them to succeed in concurrent personal, family and professional roles. Flexible career paths, mentoring and support of various types are important. The final task is to foster among women an optimistic and open view of involvement in the profession. The need is paramount for women and those who train and employ them to understand the advantages of inclusion at all levels - in education, training, research, clinical care and policy making (Sood \& Chadda, 2009).

\section{The role of psychiatric societies}

Women are an active group in national psychiatric associations around the world and in the WPA. Many have support from male colleagues in their work and lives. We have the opportunity to ask colleagues to record their experiences and ideas about the needs for women in psychiatry in various countries. In this way women and men can learn from each other and plan for change that is consistent with professional values.

\section{Looking to the future}

While fewer people would now argue with the advantages of women having the opportunity to contribute fully to psychiatry, there is a long way to go in making this a reality. It is important to continue to gain a better understanding of the needs and challenges of women in the profession. Armed with this knowledge and by keeping in mind that traditional or rigid working conditions may not lead to the most desirable outcomes, educators, employers and policy makers will be able to foster working and training environments that ultimately are likely to benefit both men and women, as well as patients and their families.

\section{Acknowledgements}

I thank Kaveh Monshat and Neda Monshat and anonymous reviewers for comments and contribution.

\section{References}

Allen, I. (2005) Women doctors and their careers: what now? BMJ, 331 569-572.

Bogan, A. M. \& Safer, D. L. (2004) Women in psychiatric training. Academic Psychiatry, 28, 305-309.

Borus, J. F. (2004) Women and academic psychiatry. Academic Psychiatry, 28, 278-281.

Chandra, P., Herrman, H., Fisher, J. E., et al (2009a) Contemporary Topics in Women's Mental Health: Global Perspectives in a Changing Society. Wiley-Blackwell.

Chandra, P. S., Satyanarayana, V. A. \& Carey, M. P. (2009b) Women reporting intimate partner violence in India: associations with PTSD and depressive symptoms. Archives of Women's Mental Health, 12, 203-209.

Hirshbein, L. D. (2004) History of women in psychiatry. Academic Psychiatry, 28, 337-343.

Howard, L. (2003) Women in academic psychiatry. Psychiatric Bulletin. 27, 321-322.

Nagaraja, D. \& Murthy, P. (2008) Mental Health Care and Human Rights. National Human Rights Commission (New Delhi)

Niaz, U. \& Hassan, S. (2006) Culture and mental health of women in South-East Asia. World Psychiatry, 5, 118-120.

Ramsay, R. (2005) Women in psychiatry: ten years of a special interest group. Advances in Psychiatric Treatment, 11, 383-384.

Robinson, J. (2009) Bluestockings: The Remarkable Story of the First Women to Fight for an Education. Viking.

Sood, M. \& Chadda, R. (2009) Women in psychiatry: a view from the Indian subcontinent. Indian Journal of Psychiatry, 51, 199-201.

Stewart, D. E. (2006) The International Consensus Statement on Women's Mental Health and the WPA Consensus Statement on Interpersonal Violence Against Women. World Psychiatry, 5, 61-64.

Stewart, D. E., Dorado, L. M., Diaz-Granados, N., et al (2009) Examining gender equity in health policies in a low- (Peru), middle- (Colombia), and high- (Canada) income country in the Americas. Journal of Public Health Policy, 30, 439-454.

Thara, R., Kamath, S. \& Kumar, S. (2003) Women with schizophrenia and broken marriages - doubly disadvantaged? Part II: family perspective. International Journal of Social Psychiatry, 49, 233-240.

Vijayakumar, L., Pirkis, J. \& Whiteford, H. (2005) Suicide in developing countries (3): prevention efforts. Crisis, 26, 120-124.

\title{
Child soldiers
}

\section{David Skuse}

Behavioural and Brain Sciences Unit, Institute of Child Health, London, UK, email dskuse@ich.ucl.ac.uk

O ver the past 20 years the number of children recruited into armed conflict, as combatants, spies, labourers and sex slaves, has increased substantially (Wessells, 2009). In this issue, we focus on the research that has been done in recent years to identify the extent of this problem and, in particular, the efforts that are being made to discover the most effective ways of rehabilitating former child soldiers into society.
Aoife Singh and Ashok Singh have reviewed evidence on the mental health consequences of being a child soldier, which can be summarised as comprising mainly posttraumatic stress disorder, depression, anxiety and substance misuse. Child soldiers are not a homogeneous group. Their outcomes are likely to be influenced by their experiences before, during and after the conflict. There will be substantial differences in terms of the length of time they 
spent with an armed group, their experiences within that group and the degree and quality of post-conflict support they receive. Wessells (2009) suggests that the majority of former child soldiers exhibit significant resilience, but the extent to which they can successfully be reintegrated into their community of origin strongly influences longer-term adjustment. Thus, there are many potentially exacerbating and mitigating factors that render unwise generalised statements concerning the degree of risk to child soldiers' mental health.

Brandon Kohrt and his colleagues agree that we know little of the needs or efficacy of interventions to support former child soldiers and aid their social integration. They describe lessons learned from their work with the Transcultural Psychosocial Organization in Nepal, where both insurgent Maoist groups and government forces conscripted large numbers of children. Because their intervention was with conflict-exposed children in general, not just with those who had been soldiers, they address some of the questions raised by the Singh review.

Kohrt and colleagues emphasise that, for some children who participated in armed groups, it is the experiences they have after returning home that are the most troubling and liable to provoke a deterioration in mental health. Ways of managing their reintegration, to optimise outcomes, are discussed in a fascinating review by Theresa Betancourt of her work in Sierra Leone, which has followed up former child soldiers for the best part of a decade. She concludes that services should be based on need rather than labels; all three articles concur on that important point.

\section{Reference}

Wessells, M. (2009) Supporting the mental health and psychosocial wellbeing of former child soldiers. Journal of the American Academy of Child and Adolescent Psychiatry, 48, 587-590.

\section{The mental health consequences of being a child soldier - an international perspective}

\section{Aoife R. Singh ${ }^{1}$ and Ashok N. Singh ${ }^{2}$}

${ }^{1}$ FY1 doctor in Leicester, UK, email aoifesingh@hotmail.co.uk; ${ }^{2}$ Consultant Psychiatrist, Pilgrim Hospital, Boston, UK

W orldwide there are currently 300000 child soldiers. Not only does the use of child soldiers lead to individual suffering but it also alters the dynamics of war and makes conflict and instability more likely. It is important both to prevent recruitment and to rehabilitate former child soldiers into their communities. For rehabilitation and reintegration programmes to be effective, it is necessary to understand the consequences of child soldiering. This paper reviews and summarises some of the key findings related to the mental health consequences of being a child soldier.

The use of children in fighting forces is not a new phenomenon. Their use was documented in the Old Testament of the Bible - for example David's service to King Saul - as well as in Greek mythology (such as the story of Hercules and Hylas), philosophy and literature. In more recent times, children fought for and against the Nazis in the Second World War. However, in the post-Cold War era, the use of child soldiers has increased dramatically. This increase is linked to various factors, such as the development of lightweight firearms, which can be handled by children as young as 10 years, the metamorphosis of conflict from a predominately inter-state into a predominately long-term, low-intensity intra-state phenomenon, and the undermining of social structures by catastrophes such as HIV/AIDS.

The term 'child soldier' was defined by the United Nations Children's Fund (UNICEF) in the Cape Town Principles as 'any person under 18 years of age who is part of any kind of regular or irregular armed force in any capacity' (UNICEF, 1997), and that definition is followed here.

\section{Method of review}

Various electronic databases were searched, including MEDLINE (1966 to present), EMBASE, CINAHL, IBSS, ALTA, EconLIT and PsycLIT. In addition, the websites of the main organisations involved with child soldier advocacy were searched, for example those of the United Nations, the Coalition to Stop the Recruitment of Child Soldiers, Amnesty International and the United States Agency for International Development (USAID).

\section{Key findings}

The key mental health consequences reported in the literature were related to post-traumatic stress disorder (PTSD), the ability of child soldiers to become normal socialised adults, and alcohol and drug misuse.

\section{Post-traumatic stress disorder}

Derluyn et al (2004) interviewed 301 Ugandan former child soldiers. Of the 71 who completed the self-report Impact of Event Scale for PTSD, 69 (97\%) reported post-traumatic stress reactions of clinical importance. The authors concluded that 